\title{
Criatividade em programas de pós-graduação em Educação: práticas pedagógicas e fatores inibidores
}

\author{
Vivianne Bezerra Figueiredo Lima - Universidade Católica de Brasilia, Brasilia \\ Eunice M. L. Soriano de Alencar - Universidade de Brasilia, Brasilia
}

\begin{abstract}
Resumo
Este estudo investigou procedimentos pedagógicos que favorecem o desenvolvimento e expressão da criatividade discente, utilizados por professores de programas de pós-graduação em educação e fatores que dificultam promover tal expressão. Foram entrevistados 15 professores de universidades públicas, sendo os dados submetidos à análise de conteúdo. Os resultados indicaram distintas práticas pedagógicas utilizadas pelos docentes favorecedoras da criatividade dos estudantes, sendo instigar o aluno por meio de desafios e questionamentos a mais frequente. Os fatores mais destacados como entraves à promoção da criatividade foram relativos ao aluno. Entre eles, apontam-se lacunas na formação discente e medo de se expressar. Outros fatores referiam-se ao professor, como falta de tempo e falhas na formação, e ainda outros relativos à instituição de educação superior e aos órgãos que regulamentam a pós-graduação. Dada a diversidade de elementos identificados como cerceadores da criatividade discente, conclui-se pela necessidade de maior estímulo à criatividade em cursos de pós-graduação.

Palavras-chave: Criatividade, Professor, Pós-graduação, Educação superior.
\end{abstract}

\section{Creativity in graduate programs in education: Pedagogical practices and inhibiting factors}

\begin{abstract}
This study investigated pedagogical practices that foster the development and expression of students' creativity, implemented by professors from graduate programs in education, and factors that hinder the promotion of the creative expression. Fifteen professors from public universities were interviewed and the data was submitted to content analysis. The results indicated several pedagogical practices used by the professors to stimulate the expression of students creativity. Instigating the students through challenges and questions was the most frequent practice pointed out. The most indicated factors as impediment to the promotion of creativity regarded the student, among which we can mention gaps in the previous training and fear of expressing ideas. Other factors were related to the professor, such as lack of time and flaws in previous training, and others related to the higher education institution and agencies that regulate graduate courses. The diversity of features identified as inhibitors to students' creativity highlights the need of more incentive to creativity in graduate courses.
\end{abstract}

Keywords: Creativity, Professor, Graduate education, Higher education.

\section{Creatividad en programas de posgrado: prácticas pedagógicas y factores inhibidores}

\section{Resumen}

Este estudio investigó los procedimientos pedagógicos que favorecen el desarrollo y la expresión de la creatividad estudiantil, utilizados por profesores de posgrado en educación, y factores que dificultan esta expresión. Se entrevistaron 15 profesores de universidades públicas, y los datos fueron sometidos a un análisis de contenido. Los resultados mostraron diferentes prácticas pedagógicas utilizadas por los docentes que favorecen la creatividad de los estudiantes, siendo instigar los estudiantes a través de desafíos y cuestionamientos la más frecuente. Los factores más indicados como barreras para la promoción de la creatividad se relacionaron con el alumno, entre ellos se señalan las lagunas en la formación discente y el miedo de expresarse. Otros factores se relacionaron al profesor, como la falta de tiempo y lagunas en la formación, y otros referentes a la institución de educación superior y a los órganos que regulan el posgrado. Ante la diversidad de elementos identificados como inhibidores de la creatividad discente, se concluye por la necesidad de mayor incentivo a la creatividad en cursos de posgrado.

Palabras clave: Creatividad, Profesor, Posgrado, Educación superior.

\section{Introdução}

Uma análise da literatura sobre criatividade na educação indica um número crescente de autores que têm sublinhado a necessidade de uma atenção maior ao desenvolvimento da capacidade criativa na educação superior (Alencar, 2011; Alencar \& Fleith, 2010a; David, Nakano, Morais \& Primi, 2011; Gibson, 2010; Hosseini, 2011; Jackson, Oliver, Shaw \& Wisdom, 2007;
Sathler \& Fleith, 2010). Uma das justificativas para tal é o reconhecimento do papel da criatividade no processo de preparação dos jovens para o mundo incerto e complexo do trabalho, o qual exige profissionais aptos a resolver problemas imprevisíveis, utilizando a sua capacidade criativa. Tem sido também lembrado por autores, como Alencar e Fleith (2010a), Jackson (2006), Jackson e cols. (2007), ser a criatividade um elemento essencial na sociedade do conhecimento, dada a sua contribuição 
para a produção de novos saberes. A sua importância é de tal ordem, que, segundo Moran (2010), diversos líderes governamentais têm argumentado ser a sobrevivência das sociedades modernas dependente do grau em que valorizam e fomentam o desenvolvimento e expressão da criatividade. Em decorrência, planos têm sido estabelecidos para estimular a criatividade na educação e economia. Uma iniciativa nesta direção foi, por exemplo, o projeto "Criatividade na Educação Superior", desenvolvido pela Associação Europeia de Universidades. Participaram desse projeto, representantes de instituições de educação superior de 21 países, os quais foram incumbidos de realizar um trabalho em cooperação com o objetivo de examinar um elenco de condições que poderia promover ou inibir a criatividade na educação superior, com foco em tópicos diversos, como inovação no ensino e aprendizagem, e instituições de educação superior criativas, sua estrutura e liderança (European University Association, 2007).

Paradoxalmente, apesar do reconhecimento de que é necessário desenvolver a capacidade criativa dos estudantes da educação superior com vistas a prepará-los para um futuro incerto, há concordância entre distintos autores de que a criatividade não tem recebido a atenção devida (Alencar \& Fleith, 2009, 2010b; Castanho, 2000; Csikszentmihalyi, 2007; David e cols., 2011, Jackson, 2006, 2007; Wechsler, 1998, 2002), considerando-se urgente um incentivo maior à promoção da criatividade nesse nível de ensino. Vários entraves ao florescimento da criatividade na educação superior têm sido também apontados. Jackson (2006) lembra, por exemplo, que muitos professores da educação superior têm conhecimento limitado sobre a diversidade de estratégias que poderiam utilizar para estimular a criatividade no ensino de suas disciplinas e ainda que muitos deles valorizam a criatividade apenas em um nível retórico. Esse autor sinaliza resistência do corpo docente e de estudantes a propostas inovadoras; elementos organizacionais de natureza estrutural, cultural e processual, escassez de tempo e de recursos, além de políticas governamentais, como entraves à expressão da criatividade na educação superior. Alguns desses fatores foram também observados por Fryer (2007) em um estudo com 90 docentes, os quais indicaram carga excessiva de trabalho, recursos limitados, além de grande número de alunos em sala de aula e tempo insuficiente para contato com os alunos, entre outros fatores, como restritores à criatividade na educação superior.

Mais recentemente, em estudo realizado por Alencar e Fleith (2010b), com uma amostra de 338 docentes de distintas áreas do conhecimento, que responderam a uma checklist de barreiras à promoção de condições favoráveis á criatividade na prática docente, constatou-se que barreiras relacionadas ao aluno foram as apontadas por maior número de professores, incluindo alunos com dificuldade de aprendizagem, desinteresse discente pelo conteúdo ministrado, elevado número de alunos em sala de aula. Outras também sinalizadas por expressivo número de participantes diziam respeito ao docente, como poucas oportunidades para discutir e trocar ideias com colegas de trabalho sobre estratégias instrucionais e elevado número de disciplinas e outras atividades, limitando tempo de preparação para a prática docente. Barreiras relacionadas ao aluno foram ainda as mais indicadas por professores do curso de Letras, em estudo desenvolvido anteriormente por Oliveira e Alencar (2007). Participaram desse estudo 20 docentes, os quais, ao serem inquiridos em entrevista sobre entraves ao desenvolvimento da criatividade discente, apontaram, em referência ao aluno, a timidez, o cansaço, especialmente daqueles de cursos noturnos, desmotivação para a disciplina, resistência à mudança e ao novo, além de despreparo. Outras barreiras sinalizadas com menor frequência foram referentes à instituição, como carência de materiais; aos colegas, como resistência à criatividade; e ainda outras relativas à própria formação recebida, de caráter tradicional, que, segundo os participantes, predominava nos cursos de formação de professores, inclusive no de Letras. De forma similar, Vianna e Alencar (2006), em pesquisa com professores de cursos de graduação online, verificaram que barreiras referentes ao aluno, como desinteresse pelo conteúdo do curso e estudantes com dificuldades de aprendizagem, estavam entre as mais indicadas.

Uma inspeção da literatura sobre criatividade na educação superior indica que, apesar do número crescente de pesquisas já realizadas, poucas delas tiveram como foco a criatividade em cursos de pós-graduação stricto sensu. Entre os estudos disponíveis, apontam-se os desenvolvidos por Alencar (2002), Barreto e Martínez (2007) e Oliveira (2012). O primeiro deles teve como participantes 92 estudantes de mestrado e doutorado. Investigou a percepção desses estudantes a respeito do estímulo à criatividade por parte de seus professores. Diferindo de dados obtidos com relação a esse mesmo aspecto junto a uma amostra de estudantes de graduação (1997), constatou-se que os pós-graduandos consideraram que seus professores apresentavam maior incentivo à criatividade, propiciando, por exemplo, um ambiente mais favorável à expressão de novas ideias, 
comparativamente a estudantes de graduação. Barreto e cols. (2007), em estudo de caso de quatro professores que atuavam na pós-graduação stricto sensu, examinaram as possibilidades de práticas criativas e inovadoras de ensino nos programas em que estavam inseridos. As autoras constataram uma compreensão embrionária acerca de criatividade por parte dos docentes e ainda um conjunto de elementos, alguns deles que facilitam uma prática criativa, como uso do lúdico em suas aulas, e outros dificultadores, como escassez de tempo para utilizar procedimentos docentes mais criativos. Por outro lado, Oliveira (2012) investigou concepções de criatividade e procedimentos pedagógicos utilizados para o desenvolvimento do potencial criativo discente em uma amostra de 20 professores e 20 estudantes de distintos cursos de pós-graduação. Embora vários docentes tenham indicado práticas docentes consideradas por eles como promotoras da criatividade, como incentivo ao diálogo e exercícios de reflexão e crítica, a grande maioria sinalizou desconhecer o tema da criatividade no ensino ou ter um conhecimento muito limitado sobre o mesmo. Ademais, vários dos estudantes entrevistados apontaram práticas docentes deletérias ao desenvolvimento da criatividade discente nas disciplinas que cursavam, como, por exemplo, exigência de trabalhos rotineiros, críticas do professor a novos posicionamentos por parte do aluno, restrição da autonomia discente, além de rigidez dos programas adotados.

Com base na literatura consultada, considera-se que há muito ainda a investigar sobre criatividade em cursos de pós-graduação. Necessário, por exemplo, explorar com maior profundidade algumas questões referentes à promoção de criatividade em cursos específicos de pós-graduação e os principais entraves a essa promoção. Dada a relevância do tema e com vistas a ampliar as informações sobre criatividade na prática docente na pós-graduação, desenvolveu-se o presente estudo. Este teve como objetivos investigar o uso de práticas pedagógicas que favorecem o desenvolvimento e expressão da criatividade do estudante por professores de cursos de pós-graduação stricto sensu em Educação em suas disciplinas, e fatores que dificultam promover condições adequadas ao desenvolvimento e expressão da capacidade criativa discente nesses cursos.

\section{Método}

\section{Participantes}

Participaram da pesquisa 15 professores de cursos de pós-graduação stricto sensu em Educação de duas universidades públicas, localizadas no nordeste do Brasil. Entre os 15 participantes, sete eram do gênero masculino $(46,67 \%)$ e oito $(53,33 \%)$ do gênero feminino, com idade entre 38 e 70 anos $(\mathrm{M}=53,73)$. No tocante à formação acadêmica dos professores, nove eram graduados em Pedagogia, quatro deles tendo também concluído um segundo curso superior (Estatística, Filosofia, História e Matemática); os demais haviam cursado Arquitetura, Educação Física, Letras, Matemática, Música e Serviço Social. Doze entre os 15 participantes tinham Doutorado em Educação, um em Sociologia da Educação, um em Ecologia e um em Matemática.

A carga horária de trabalho semanal na pós-graduação variou de $3 \mathrm{~h}$ a $40 \mathrm{~h}(\mathrm{M}=26,9 \mathrm{~h})$. Entretanto, dois dos 15 professores não informaram esse dado. Um deles ressaltou que trabalhava pela manhã, à tarde, à noite e até de madrugada, tendo salientado, ainda, que tinha 10 orientandos e coordenava várias pesquisas de campo. O outro professor pontuou que, se fosse contabilizar as horas trabalhadas por semana, estas passariam de $100 \mathrm{~h}$ semanais.

No que tange ao tempo de experiência como docente na pós-graduação, um professor desempenhava a função há apenas um ano; um há três anos; um há quatro anos; dois há cinco anos; um há seis anos; um há oito anos; três há 10 anos; um há 12 anos; um há 18 anos; um há 20 anos; e dois há 31 anos ( $M=11,6$ anos). Quanto ao grau de satisfação profissional como professor da pós-graduação, em uma escala de um a dez, um docente atribuiu o valor quatro; dois o valor sete; quatro atribuíram o valor oito; três o valor nove e cinco apontaram o valor 10 de satisfação.

\section{Instrumento}

Utilizou-se para coleta de dados a entrevista semiestruturada, cujo protocolo constituiu-se de duas partes. A primeira era composta por questões para levantamento de dados biográficos dos participantes (nome, gênero, idade, formação acadêmica, tempo de atuação na pós-graduação, carga horária semanal, tipo de instituição superior onde trabalhava) e uma questão referente ao grau de satisfação como professor de pós-graduação stricto sensu. A segunda parte incluía 12 perguntas relacionadas ao fenômeno investigado, com questões referentes ao uso de práticas pedagógicas que favorecem o desenvolvimento da criatividade discente utilizadas pelos professores e fatores que dificultavam propiciar condições adequadas ao desenvolvimento da capacidade criativa de estudantes de pós-graduação. 


\section{Procedimento}

Primeiramente foi feito contato, por telefone, com a direção dos dois cursos de pós-graduação stricto sensu em educação, a fim de marcar uma visita para apresentar o projeto de pesquisa e solicitar a participação dos docentes do programa. Foi encaminhada, por sugestão de um dos diretores de curso, uma carta de apresentação redigida pela primeira autora, expondo, detalhadamente, os objetivos e a relevância da pesquisa, o instrumento que seria utilizado para a coleta de dados e assegurando a confidencialidade, assim também, requerendo a autorização da coordenação para sua efetivação. Foram encontradas dificuldades para efetivação da pesquisa no que diz respeito a um retorno por parte dos professores de uma universidade e a inflexibilidade do coordenador de uma segunda universidade. Este se recusou a viabilizar um contato com os docentes, sugerindo à primeira autora que enviasse um e-mail aos professores solicitando sua colaboração no estudo. Entrou-se em contato por e-mail e por telefone com os professores, marcando um encontro para maiores esclarecimentos sobre os objetivos da pesquisa; entretanto, muitos não compareceram.

A participação no estudo foi voluntária, tendo sido assegurado aos participantes o caráter confidencial das respostas fornecidas e informado que os dados seriam analisados coletivamente, cumprindo, assim, as exigências éticas legais. As entrevistas foram realizadas nas instituições de ensino superior onde 14 professores trabalhavam, em horários previamente agendados. Um dos participantes optou por ser entrevistado em sua residência. Todos os docentes assinaram o termo de consentimento livre e esclarecido.

O tempo médio de duração da entrevista foi de 54 minutos, com uma variação de 34 minutos a $1 \mathrm{~h}$ e 37 minutos. Todas as entrevistas foram conduzidas pela primeira autora da pesquisa, tendo sido gravadas e posteriormente transcritas verbatim.

\section{Análise dos dados}

Os dados obtidos por meio das entrevistas semiestruturadas foram submetidos à análise de conteúdo, seguindo-se recomendações de Bardin (2004) e Bauer (2008). Com base na leitura das respostas às distintas questões, foram identificados temas comuns, tendo em vista a categorização dos mesmos.

Na primeira fase, organizou-se o material das entrevistas, elaborando os indicadores, a partir da presença frequente de menções explícitas a distintos temas que posteriormente possibilitaram a construção de categorias. $\mathrm{Na}$ segunda etapa, organizaram-se quadros a partir das respostas dos entrevistados utilizando-se codificação, enumeração e categorização. Na codificação, foram identificadas as unidades de registro presentes nos conteúdos das respostas dos entrevistados, privilegiando o tema. Quanto à categorização, agrupou-se por categoria semântica, reunindo em uma mesma categoria todas as respostas que diziam respeito a um mesmo tema.

\section{Resultados}

\section{Práticas pedagógicas utilizadas pelo professor para estimular a criatividade discente}

Uma análise das respostas à pergunta referente a se utilizavam nas disciplinas de pós-graduação práticas pedagógicas que favorecem o desenvolvimento e expressão da criatividade discente e, em caso afirmativo, enumerá-las, indicou que todos os participantes responderam afirmativamente, apontando um ou mais procedimentos docentes. A prática indicada por maior número de professores $(\mathrm{n}=8)$ foi a de instigar o estudante por meio de questionamentos e desafios. Seguem duas respostas obtidas:

Eu uso discussões a partir da leitura de texto que o aluno lê antes e ai eu vou colocando questões para que os alunos participem. Então eu vou questionando, para que o aluno vá refletindo o trabalho que é dele. (P2)

Instigar o saber do outro é um ato criador e um ato que possibilita a criação, não é? [...] Eu acho que criar desafios. No momento em que você cria desafios baseados nas situações que a educação boje está... (P7)

A utilização de filmes, obras literárias, encenações, música, videoclip, desenho ou poesia foi mencionada por quatro dos 15 professores. Tais recursos, segundo os participantes, são utilizados para que ocorra uma contextualização. Seguem falas ilustrativas:

Eu, agora, estou usando muito o cinema e a literatura. Eu passo alguns textos básicos da área que nós estamos estudando e sempre passo um filme ou uma obra literária para eles fazerem o confronto. (P15)

Representar aquilo que estamos lendo através da representação, como teatro. (P2) 
Dos 15 participantes da pesquisa, quatro relataram a relevância em promover um clima propício à interação como forma de facilitar a expressão discente $\mathrm{e}$, concomitantemente, a criatividade, como ilustrado na seguinte resposta:

Os alunos estão condicionados, eles não abrem a boca, por mais que você estimule. Ai, depois é que vão tomando alguma confiança. Têm medo de falar alguma coisa e ser besteira... Tem que haver um clima de interação que desenvolva essa confiança. É importante criar esse clima. (P9)

Trazer a realidade, o cotidiano e fazer uma relação com o conteúdo tratado em aula foi uma prática citada por dois professores e possibilitar o diálogo dos alunos com os teóricos discutidos na disciplina foi um procedimento apontado por um participante. Este mencionou que essa prática estimula o estudante a produzir conhecimento. Ademais, três professores deram exemplos de outras práticas, consideradas por eles, como criativas. Um deles apresentou o que denominou de "grupos aprendentes". Outro descreveu como realiza um júri simulado, enquanto um terceiro expôs o que ele intitulou de "aula errada". Este destacou que intencionalmente cometia muitos erros, para instigar o senso crítico do aluno e levá-lo a não acreditar cegamente na fala do professor.

Fatores que dificultam a promoção do desenvolvimento e expressão criativa de estudantes de pós-graduação

Uma análise das respostas referentes aos fatores que dificultam a promoção do desenvolvimento e expressão da criatividade discente indicou que esses fatores se relacionavam ao aluno $(35,63 \%)$, ao professor $(33,33 \%)$, à instituição $(21,84 \%)$ e aos órgãos que regulamentam o ensino superior $(9,20 \%)$. A categoria com maior número de respostas foi a relativa ao aluno, como, por exemplo, lacunas na sua formação anterior, acomodação e intolerância a propostas inovadoras. Com relação ao professor, falta de tempo por excesso de trabalho, padronização em relação ao formato das aulas, acomodação e falhas na formação anterior foram algumas das respostas apresentadas. Vários docentes mencionaram também elementos presentes na instituição onde atuavam, como exigência de carga horária muito elevada e omissão em relação à criatividade, tendo sido ainda sinalizados fatores relativos aos órgãos que regulamentam a pós-graduação, como, por exemplo, exigência de uma produção científica intensa, em termos de publicações (ver Tabela 1).
Seguem algumas das falas dos professores que ilustram as distintas categorias:

- Relacionadas ao aluno

A postura discente vem de uma educação tradicional, onde a criatividade não é estimulada. Os alunos reproduzem o que o professor e os livros ditam. Ao chegarem na pós-graduação, eles não sabem se expressar. (P2)

A falta de conbecimento do aluno é uma barreira muito grande. A criatividade está associada à experiência, e a experiência na academia é leitura e estudo. (P15)

Porque... presta atenção que você já vem que nem um roboz̧inho! Nos próprios alunos, eu sinto muito isso. Como eu sou muito inventiva, fico inventando coisas, os próprios alunos perguntam "Ô professora, pra que tudo isso?" É quase... Vamos fazer só o feijão com arroz, mesmo! (P10)

Com respeito, muitas vezes, à formação. Existe a questão das leituras. O pessoal tem muito pouca leitura quando entra no mestrado, quando entra no doutorado. (P4)

Não é fácil não. Porque normalmente o aluno vem de uma construcãa de que ele sabe que discordar do professor é perigoso.... É difícil para eles a autoexpressão, porque eles estão acostumados a não discordar do professor, e a não poder pensar diferente. (P.6)

Relacionadas ao professor

Diria que o grande problema do professor é se acomodar a essas situacões. Ele é estimulado a fazer o contrário, quer dizer, quanto menos criativo, quanto mais rotina, melhor, porque ele tem uma redução de trabalho e um aumento de ganho. Então eu diria que a própria lógica do sistema também estimula isso. (P7)

A formação do professor foi pra concordar. Não foi pra gerar discórdia... Estudar por xerox, repetir o que o professor pediu que ele repetisse. (P15)

Existe uma arrogância muito grande na universidade como um todo, entre os profissionais docentes universitários. $\mathrm{Na}$ pós-graduação, isso é agravado. Porque na pós-graduação, aqui, nós só temos doutores e pós-doutores. (P6)

Uma vez eu fiz uma experiência boa na pós-graduação oferecendo narrativa como método e muita arte. Trabalhando assim, eu ficava sempre com receio, medo mesmo! (P13) 
Tabela 1. Fatores Dificultadores à Promoção do Desenvolvimento e Expressão da Criatividade Discente

\begin{tabular}{lcc}
\hline Elementos dificultadores & $f$ & $\%$ \\
\hline Aluno & 31 & 35,63 \\
\hline Acomodação & & \\
Dificuldade na escrita & & \\
Dificuldade na interpretação de textos & & \\
Dificuldade na leitura em língua estrangeira & & \\
Falta de leitura & & \\
Falta de vivência profissional & & 33,33 \\
Lacunas na formação anterior & & \\
Intolerância a propostas inovadoras & & \\
Medo ou dificuldade de se expressar & & \\
Medo de discordar do professor & &
\end{tabular}

Acomodação

Crítica negativa por parte dos pares às práticas criativas

utilizadas pelo docente

Dificuldade em construir as próprias metodologias

Excessiva flexibilização na avaliação dos alunos que ingressam

na pós-graduação stricto sensu

Falhas na formação anterior

Falta de apoio dos demais docentes

Falta de sensibilidade

Falta de tempo por excesso de trabalho

Medo de se expor ou de ousar

Muita cobrança em relação às funções que devem ser desempenhadas

Padronização em relação ao formato das aulas

Pedantismo, arrogância ou excessiva vaidade

Ser taxado de bobo, ridículo, infantil ou de estar preenchendo tempo

Tendência a um pensamento unilateral

\begin{tabular}{lcc}
\hline Elementos dificultadores & f & $\%$ \\
\hline Instituição & 19 & 21,84 \\
\hline
\end{tabular}

Ausência de cursos, seminários ou workshops oferecidos aos professores

Burocracia

Exigência de carga horária muito pesada

Falta de recursos materiais

Muito atrelada ao convencional

Omissão em relação à criatividade

Rigidez na organização dos espaços/estruturação das salas

Status quo que inibe a prática criativa docente

$\begin{array}{lcc}\text { Órgãos que regulamentam a pós-graduação } & 8 & 9,20\end{array}$

Cobrança em relação às múltiplas funções exercidas pelo professor

Exigência de uma produção intensa

\begin{tabular}{llll}
\hline Total & 87 & 100,00 \\
\hline
\end{tabular}

Nota: A porcentagem foi calculada com base na frequência dos elementos dificultadores à promoção do desenvolvimento e expressão da criatividade discente e não a partir do número de entrevistados. 
Relacionadas à instituição

A própria burocracia da universidade, a organização dos espaços, a estruturação da sala de aula. Eu acho que a gente tem avançado alguma coisa, mas tudo isso tende a estimular essa situação de omissãa, de não envolvimento, de não compromisso com a mudança. Porque eu acho que a criatividade traz muito perigo, né? Para as instituições instituidas, né? (P7)

Um professor criativo em sala de aula, ele é engessado pelo status quo, pelo modelo que está lá. Por exemplo, um professor criativo em sala de aula, que dinamiza a sala de aula, os alunos fazem barulho, farem bagunç, mas uma bagunça organizada. Uma bagunça criativa. E isso implica que o estatuto do status quo dir que aula boa tem que ser aula bem comportada. Em que os alunos têm que ficar sentados e eles confundem criatividade com disciplina.

Por exemplo, um espaço para projeção de um filme, tudo é muito complicado. Até o uso de data-show, o recurso é hoje absolutamente simples, não é? Até o uso de um data-show é complicado. Ou não tem em quantidade suficiente e, quando tem, está sempre faltando alguma coisa. Então nós temos dificuldades materiais mesmo, de recursos materiais, dificuldade de espaço. (P10)

- Relacionadas aos órgãos que regulamentam a pós-graduação

Eu acho que esse é um problema muito sério (número de artigos publicados)! Isso vem a barrar. Isso é que era o estímulo à criação passa a ser um obstáculo à criação. Você tem que ter uma produção intensa, você passa a fazer isso como um projeto de sobrevida, uma obrigação, enfim, eu acho que isso é um empobrecimento do ato criador. (P7)

\section{Discussão}

Um dos objetivos deste estudo foi investigar o uso, por parte de professores de cursos de pós-graduação em educação, procedimentos pedagógicos que favorecem o desenvolvimento e expressão da criatividade discente. Várias práticas foram citadas pelos participantes, as quais têm sido apontadas por especialistas da área, como Alencar (2000), Alencar e Fleith (2009), Fleith (2002, 2007), Cropley (2005), Jackson (2006), Souza (2008) e Wechsler (2002) como estimuladoras da capacidade de pensar de forma criativa dos estudantes, independentemente de estarem cursando o ensino fundamental, médio ou superior. Esses autores apresentam como sugestões aos educadores alguns procedimentos pedagógicos, como levar em conta os conhecimentos prévios dos alunos; implementar atividades que ofereçam desafios, reservar tempo para o diálogo; diversificar as estratégias docentes utilizadas em sala de aula, valorizar a expressão de novas ideias, manter uma relação positiva com os alunos e criar um ambiente psicologicamente seguro, no qual os alunos não tenham medo de se expor. Os docentes que participaram da pesquisa aqui descrita sinalizaram, entre outros procedimentos, questionar e desafiar o aluno, diversificar as estratégias docentes, utilizando, por exemplo, recursos, como filmes e obras literárias, promover um clima propício à interação e relacionar o conteúdo tratado na disciplina com a realidade. Como a criatividade envolve gerar e interligar ideias, além de avaliar o valor das mesmas, poder-se-ia considerar que os docentes entrevistados têm buscado desenvolver, em suas disciplinas, tais habilidades. Esses aspectos são relevantes na formação do pesquisador, um dos objetivos da pós-graduação stricto sensu. Entretanto, esses procedimentos têm sido utilizados pelos docentes fundamentalmente para facilitar a aprendizagem dos alunos e não com o objetivo explícito de desenvolver o seu potencial criativo. Isso está em sintonia com o observado por Barreto e Martínez (2007), as quais constataram interesse de professores de pós-graduação pelo uso de metodologias diferenciadas, como dinâmica de grupo e atividades lúdicas, no sentido de promover a aprendizagem dos estudantes.

É notório que os dados foram coletados junto a professores de mestrado e doutorado em educação. Entretanto, conforme lembrado por vários dos participantes, a criatividade não foi objeto de estudo nos seus cursos de formação de origem. Nesse sentido, uma participante chegou a ressaltar que nunca tinha pensado na temática da criatividade, tendo sido na entrevista a primeira vez que ela se deteve a refletir sobre o tema. Isso é um indicador de ser a criatividade um tema pouco discutido inclusive nos cursos da área de educação, não sendo explicitamente reconhecida como um componente relevante nas propostas educacionais voltadas tanto para a formação do professor como do pesquisador. Tais resultados estão em consonância com o que foi também constatado por Oliveira e Alencar (2007), em estudo realizado com professores do curso de Letras e por Oliveira (2012) em pesquisa com docentes de distintos cursos de pós-graduação. Está ainda em sintonia com o ressaltado por Alencar (2008), Martínez (2002) e Barreto e Martínez (2007), quanto à falta de capacitação do docente no que diz respeito ao reconhecimento e desenvolvimento da capacidade de criar de 
seus alunos. Em complemento, essas autoras sinalizam a relevância de se incentivar o desenvolvimento da criatividade dos professores no período de sua formação, o que requer não apenas uma disciplina sobre criatividade no contexto educacional, mas especialmente a vivência como alunos, de práticas que posteriormente poderão utilizar em sala de aula.

Foi também objetivo deste estudo examinar fatores que, segundo os participantes, dificultam o desenvolvimento e expressão da criatividade de estudantes na pós-graduação. De forma similar ao observado em estudos anteriores com amostras de professores de cursos de graduação (Alencar e Fleith, 2010b; Oliveira e Alencar, 2007; Souza \& Alencar, 2006; Vianna e Alencar, 2006), foram os fatores referentes aos alunos os mais frequentes. Lacunas na formação anterior do estudante, além de medo/dificuldade de se expressar ou de discordar do professor, foram citados pelos participantes deste estudo. Entretanto, em pesquisas anteriormente realizadas, como as de Alencar e Fleith, 2010b, Souza e Alencar, 2006 e Vianna e Alencar, 2006, alunos com dificuldades de aprendizagem ou desinteressados no conteúdo das disciplinas ministradas foram os mais sinalizados.

Os participantes relacionaram diversos fatores referentes ao professor que se constituem entraves à promoção de condições adequadas à expressão da criatividade discente. Nota-se que, em pesquisas anteriores, tanto com amostras de docentes quanto de alunos da educação superior, alguns dos fatores referentes ao professor aqui citados foram também apontados. Um deles é a escassez de tempo devido às inúmeras tarefas que cabem ao docente realizar no seu dia a dia (Alencar \& Fleith, 2003, 2010b; Barreto e Martínez, 2007; Fryer, 2007). Também em pesquisa com estudantes de engenharia, os quais foram entrevistados sobre fatores facilitadores e inibidores da criatividade pessoal, houve menção à forma repetitiva como o ensino era conduzido por docentes como elemento inibidor à expressão criativa do estudante (Alencar \& Fleith, 2008). De forma similar, em estudos sobre características do professor facilitador e inibidor da criatividade, tanto Alencar (2000) quanto Santeiro, Santeiro e Andrade (2004) constataram que, na descrição do professor inibidor da criatividade discente por estudantes universitários, foram relacionados algumas práticas e comportamentos docentes sinalizados pelos participantes do presente estudo como cerceadores do desenvolvimento e expressão da criatividade discente. Entre eles, poder-se-iam apontar, a arrogância do professor e a padronização em relação ao formato das aulas.
Referências foram feitas, ainda, pelos docentes a elementos da instituição de educação superior, que restringem as possibilidades de um ensino facilitador da expressão criativa. Omissão com relação à criatividade, burocracia, falta de recursos materiais, entre outros, foram apontadas. Vários autores, como Jackson (2006), Alencar (2012), European University Association (2007) e Wisdom (2007), lembram que o contexto pode afetar as práticas para a criatividade tanto positiva como negativamente. Nesse sentido, Jackson ressalta que, embora os principais atores em uma sala de aula sejam professores e alunos, a cultura institucional, o valor que se dá à criatividade na prática docente e as condições de trabalho são relevantes para o florescimento da criatividade em sala de aula.

O presente estudo trouxe evidência de um conjunto de fatores que tem impacto na expressão criativa de estudantes de pós-graduação. É importante que os programas de pós-graduação que almejem maximizar o desenvolvimento da capacidade criativa de seus estudantes estejam atentos a elementos cerceadores da expressão criativa, como os citados pelos participantes. Tais elementos certamente têm impacto negativo na aprendizagem e motivação do aluno, para além da criatividade e satisfação profissional do docente. Identificá-los é a primeira etapa no processo de conduzir mudanças em direção a melhores condições ao desenvolvimento e expressão da criatividade de professores e estudantes.

Os resultados do estudo sugerem que, embora os participantes tenham relacionado algumas estratégias pedagógicas que favorecem a expressão da criatividade discente, tendo em vista a diversidade de elementos sinalizados como cerceadores da promoção de condições adequadas ao fomento da criatividade do estudante, muito necessita ser feito para que a criatividade possa estar mais presente nos cursos de pós-graduação. Necessário, por exemplo, fomentar uma cultura universitária que dê mais valor ao desenvolvimento e expressão do potencial criativo tanto de estudantes como de professores. Isso é especialmente relevante, dado que os modelos vigentes de preparação de docentes continuam profundamente arraigados em uma cultura educacional onde o espaço para a expressão criativa é ainda muito limitado. Ademais, programas para o desenvolvimento profissional continuado para docentes da educação superior são praticamente inexistentes. Há poucas oportunidades para o professor refletir, dialogar e discutir sobre suas práticas pedagógicas, constituindo-se para muitos um desafio a 
promoção de ambientes de aprendizagem que assegurem uma aprendizagem ativa e encorajem os estudantes a fazer uso da criatividade conjuntamente com outras habilidades. Muitos se queixam também das condições adversas de trabalho presentes na grande maioria das universidades brasileiras.

\section{Limitações e sugestões para futuras pesquisas}

Toda pesquisa tem limitações e este estudo não é exceção a essa regra. Uma de suas limitações diz respeito à amostra utilizada, que se caracteriza como de conveniência e com um reduzido número de participantes. Ademais, muitos dos docentes convidados para participar do estudo não se dispuseram a fazê-lo. Esses são elementos que contribuem para diminuir as possibilidades de generalização ou validade externa do estudo, não se podendo assegurar que resultados idênticos ou similares teriam sido obtidos, caso o estudo tivesse contado com a participação de todos os docentes envolvidos nos dois programas de pós-graduação em Educação em que os dados foram coletados.

Várias questões para futuras pesquisas sobre criatividade na pós-graduação são sugeridas pelos resultados obtidos neste estudo. Entre elas: há diferenças entre professores de distintos cursos de pós-graduação stricto sensu na extensão em que utilizam procedimentos docentes estimuladores da criatividade discente? Como avaliam os estudantes as práticas inovadoras de seus professores? Que elementos cerceadores da expressão criativa são mais frequentes em programas de pós-graduação de distintas áreas e de universidades públicas e particulares? Respostas a essas questões muito contribuirão para o avanço do conhecimento a respeito da criatividade na pós-graduação.

\section{Referências}

Alencar, E. M. L. S. (1997). O estímulo à criatividade no contexto universitário. Psicologia Escolar e Educacional, 1, 29-37.

Alencar, E. M. L. S. (2000). O perfil do professor facilitador e do professor inibidor da criatividade segundo estudantes de pós-graduação. Boletim da Academia Paulista de Psicologia, 19, 84-95.

Alencar, E. M. L. S. (2002). O estímulo à criatividade na pós-graduação segundo seus estudantes. Psicologia Reflexão e Crítica, 15, 63-70.

Alencar, E. M. L. S. (2008). Criatividade na educação: elementos inibidores e facilitadores. Em A. C. T.
Galvão, \& G. L. Santos (Orgs.), Educação: tendências e desafios de um campo em movimento (vol. 2, pp. 75-89). Brasília: Líber.

Alencar, E. M. L. S. (2011). Criatividade na educação superior na perspectiva de estudantes e professores. Em S. M. Wechsler \& T. C. Nakano (Orgs.). Criatividade no ensino superior: uma perspectiva internacional (pp. 180-201). São Paulo: Vetor.

Alencar, E. M. L. S. (2012, junho). O fomento da criatividade na formação de professores para o magistério superior. Trabalho apresentado no VII Congresso Iberoamericano de Docência Universitária. Porto, Portugal.

Alencar, E. M. L. S., \& Fleith, D. S. (2003). Barreiras à criatividade pessoal entre professores de distintos níveis de ensino. Psicologia: Reflexão e Crítica, 16, 63-69.

Alencar, E. M. L. S. \& Fleith, D. S. (2008). Criatividade pessoal: fatores facilitadores e inibidores segundo estudantes de Engenharia. Magis. Revista Internacional de Investigación en Educación, 1, 113-126.

Alencar, E. M. L. S., \& Fleith, D. S. (2009). Criatividade. Múltiplas perspectivas. Brasília: Editora da UnB.

Alencar, E. M. L. S., \& Fleith, D. S. (2010a). Inventário de práticas docentes para a criatividade na educação superior. Em E. M. L. S. Alencar, Bruno-Faria, M. F., \& D. S. Fleith (Orgs.), Medidas de criatividade. Teoria e prática (pp. 71-89). Porto Alegre: ArtMed..

Alencar, E. M. L. S., \& Fleith, D. S. (2010b). Criatividade na educação superior: fatores inibidores. Avaliação Psicológica, 15, 201-206.

Bardin, L. (2004). Análise de conteúdo. Lisboa: Edições 70.

Barreto, M. O., \& Martínez, A. M. (2007). Possibilidades criativas de professores em cursos de pós-graduação stricto sensu. Estudos de Psicologia, 24, 463-473.

Bauer, M. W. (2008). Análise de conteúdo clássica: uma revisão. Em M. W. Bauer, \& G. Gaskell (Orgs.), Pesquisa qualitativa com texto, imagem e som (pp. 189-217). Petrópolis: Vozes.

Castanho, M. E. L. M. (2000). A criatividade na sala de aula universitária. Em I. P. A. Veiga, \& M. E. L. M. Castanho (Orgs.), Pedagogia universitária. A aula em foco (pp. 75-89). Campinas: Papirus, 2000.

Cropley, A. J. (2005). Creativity in education and learning. London: Routledge. 
Csikszentmihalyi, M. (2007). Developing creativity. Em N. Jackson, M. Oliver, M. Shaw, \& J. Wisdom (Orgs.), Developing creativity in higher education (pp. xviii-xx). London: Routledge.

David, A. P. M., Nakano, T. C., Morais, M. F., \& Primi, R. (2011). Competências criativas no ensino superior. Em S. M. Wechsler, \& T. C. Nakano (Orgs.), Criatividade no ensino superior: uma perspectiva internacional (pp. 14-53). São Paulo: Vetor.

European University Association (2007). Report of the EUA Creativity Project 2006-2007. Bruxelas: European University Association.

Fleith, D. S. (2002). Ambientes educacionais que promovem a criatividade e a excelência. Sobredotação, 3, 27-39.

Fleith, D. S. (2007). Como desenvolver a criatividade no contexto educacional. Em SESI - Departamento Nacional (Org.), Criatividade (pp. 9-30). Brasília: SESI - Departamento Nacional.

Fryer, M. (2007). Facilitating creativity in higher education: a brief account of National Teaching Fellows' views. Em N. Jackson, M. Oliver, M. Shaw, \& J. Wisdom (Orgs.), Developing creativity in bigher education (pp. 74-88). London: Routledge.

Gibson, R. (2010). The 'art' of creative teaching: implications for higher education. Teaching in Higher Education, 15, 607-613.

Hosseini, A. F. (2011). University student`s evaluation of creative education in universities and their impact on their learning. Procedia Social and Behavioral Sciences, 15, 1806-1812.

Jackson, N. (2006). Creativity in higher education. Creating tipping points for cultural change. SCEPTrE Scholarly Paper, 3, 1-25.

Jackson, N. (2007). Imagining a different world. Em N. Jackson, M. Oliver, M. Shaw, \& J. Wisdom (Orgs.), Developing creativity in higher education (pp. 1-9). London: Routledge.

Jackson, N., Oliver, M. Shaw, M., \& Wisdom, J. (2007). (Orgs.), Developing creativity in higher education. London: Routledge.

Martínez, A. M. (2002). A criatividade na escola: três direções de trabalho. Linhas Críticas, 8,189-206.

Moran, S. (2010). The roles of creativity in society. Em J. C. Kaufman, \& R. J. Sternberg (Orgs.), The
Cambridge handbook of creativity (pp. 74-92). Cambridge: Cambridge University Press.

Oliveira, Z. M. F. (2012). Criatividade: concepções e procedimentos pedagógicos na pós-graduação stricto sensu. Tese de Doutoramento. Programa de Pós-Graduação em Educação, Universidade Católica de Brasília, Brasília, Brasil.

Oliveira, Z. M. F., \& Alencar, E. M. L. S. (2007). Criatividade na formação e atuação do professor do curso de Letras. Psicologia Escolar e Educacional, 11, 223-237.

Santeiro, T. V., Santeiro, F. R. M., \& Andrade, I. R. (2004). Professor facilitador e inibidor da criatividade segundo universitários. Psicologia em Estudo, 9, 95-102.

Sathler, T. C., \& Fleith, D. S. (2010). Estímulos e barreiras à criatividade na educação à distância. Estudos de Psicologia, 27, 457-466.

Souza, R. C. C. R (2008). Universidade, processo de ensino e aprendizagem e inovação. Em A. Galvão, \& G. L. Santos (Orgs.), Educação: tendências e desafios de um campo em movimento (pp. 57-74). Brasília: Líber Livro.

Souza, M. E., \& Alencar, E. M. L. S. (2006). O curso de pedagogia e as condições para o desenvolvimento da criatividade. Psicologia Escolar e Educacional, 10, 21-30.

Vianna, C. R. G. V., \& Alencar, E. M. L. S. (2006). Creativity and barriers to its expression in online education courses. Gifted Education International, 21, 54-62.

Wechsler, S. M. (1998). Pensando criativamente na universidade. Psicologia Escolar e Educacional, 2, 67-72.

Wechsler, S. M. (2002). A educação criativa: possibilidades para descobertas. Em S. Castanho, \& M. E. Castanho (Orgs.), Temas e textos em metodologias do ensino superior (pp. 165-170). Campinas: Papirus.

Wisdom, J. (2007). Developing higher education teachers to teach creatively. Em N. Jackson, M. Oliver, M. Shaw, \& J. Wisdom (Orgs.), Developing creativity in higher education (pp. 183-196). London: Routledge.

Recebido em: 06/11/2012

Reformulado em: 10/07/2013

Aprovado em: 21/11/2013 
Sobre as autoras:

Vivianne Bezerra Figueiredo Lima é mestre em Educação pela Universidade Católica de Brasília. Trabalha atualmente como diretora e conferencista da empresa DH2E, direcionada ao desenvolvimento humano e gerencial na área educacional.

Eunice M. L. Soriano de Alencar, Ph.D., é professora emérita e pesquisadora associada sênior do Instituto de Psicologia da Universidade de Brasília, cidadã honorária de Brasília, membro honorário do Conselho Brasileiro para Superdotação, pesquisadora do Conselho Nacional de Desenvolvimento Científico e Tecnológico (CNPq). Participa do conselho editorial de revistas especializadas em distintos países.

\section{Contato com as autoras:}

Profa. Eunice M. L. Soriano de Alencar

SHIS QL 10, conjunto 6, casa 14

71630-065 Brasília, DF

E-mail eunices.alencar@gmail.com 
